\title{
International cigarette labelling practices
}

\author{
Macksood Aftab, Deborah Kolben, Peter Lurie
}

\begin{abstract}
Objective-To describe international cigarette pack warning laws.

Design-Cross-sectional study.

Participants-Members of GLOBALink (www.globalink.org), an internet listserve for tobacco activists with members in 56 countries, who were asked to provide specific information on cigarette warning requirements in their countries.

Main outcome measures-Presence of specific warning labels, overall content score (based on a 0-10 scale with a point for each specific warning mentioned), size of warning label, location of warning label.
\end{abstract}

Results-Forty-five countries $(80 \%)$ responded; 40 had mandatory labelling requirements, three had voluntary agreements with the industry and two had no requirements. In general, American companies did no more in foreign countries than required by local law. The average developing country content score was 1.6 , compared with 5.0 in developed countries $(p=0.0003)$. Forty-two per cent of countries either had no warning requirement or had only a very general health warning. The most common warning was for heart disease ( $49 \%$ of countries) and the least common was for addiction (14\%). All warnings were more common in developed than developing countries. Warnings in developed country were on average $27 \%$ larger than those in developing countries $(p=0.325)$. Seventy-three per cent of labels in developing countries appeared only on the side of the pack, whereas $78 \%$ of labels in developed countries appeared on the front and back $(\mathrm{p}=\mathbf{0 . 0 0 3})$.

University of Michigan, Ann Arbor, Michigan, USA

M Aftab

D Kolben

P Lurie

Correspondence to: Dr P Lurie, c/o Public Citizen's Health Research Group, 1600 20th Street, NW, Washington, DC 20009

plurie@citizen.org

Received 5 November 1998 Revision received 10 May

1999

Accepted 2 June 1999
Conclusions-In almost every respect measured, residents in developing countries are receiving inferior information about the hazards of smoking than residents of developed countries. Laws should be promulgated in importing and exporting countries to ensure that, where their labelling laws differ, companies would be required to provide the more comprehensive labelling.

(Tobacco Control 1999;8:368-372)

Keywords: health warnings; cigarette pack labelling; legislation
Introduction

The World Health Organization reports that there are currently 1.15 billion regular smokers worldwide, ${ }^{1}$ equivalent to approximately a third of the global population over the age of 15. International cigarette consumption is rising dramatically. Cigarette sales in eastern Europe and the Asia/Pacific region rose 5.6\% and $8.0 \%$ respectively between 1990 and 1995 , even as smoking levels in the United States declined $4.5 \% .^{2}$ Nine hundred and forty-three million of the 1.15 billion smokers internationally are in developing countries. ${ }^{1}$

RJ Reynolds and Philip Morris, the United States' leading tobacco companies, currently sell more cigarettes in foreign countries than they do domestically. ${ }^{3}$ For example, Philip Morris sold 711.5 billion cigarettes abroad in 1997, compared with 235.2 billion cigarettes domestically. ${ }^{4}$ Its international revenues rose $68 \%$ from 1993 to $1997,{ }^{5}$ including a $12.6 \%$ increase in 1997 alone, bringing the company's international profits to $\$ 4.5$ billion.

Even at current consumption levels, the global toll of tobacco is enormous. Worldwide, tobacco is the cause of approximately 10000 deaths daily or 3.5 million annually. ${ }^{6}$ By 2020 , this number is expected to rise to 10 million per year, with seven million of these deaths occurring in developing countries. ${ }^{6}$ Tobacco now claims the lives of 2000 people a day in China alone, and the most recent studies indicate that tobacco will kill a third of all young men in China if current trends in smoking persist. $^{6}$ The number of global tobacco-related deaths per year will soon exceed those from AIDS, tuberculosis, automobile accidents, homicide, and suicide combined. ${ }^{7}$

Most tobacco control experts believe that no single factor caused the decrease in smoking rates in some Western countries in the past decade. Rather, a series of actions, including restrictions on advertising, vending machines and cigarette distribution, increased tobacco taxes, more prominent and forceful cigarette labels, and the banning of smoking in public places, combined to create a social milieu in which smoking was increasingly unacceptable.

Cigarette warning labels can be an important part of the creation of this healthier social milieu. A study conducted in Australia showed that the implementation of stronger warning labels resulted in a $27 \%$ increase in the percentage of people reporting always noticing the labels and a $7 \%$ increase in people reporting forgoing smoking due to the labels. ${ }^{8}$ 
Smokers were also better informed about the dangers of smoking after the labels went into effect. ${ }^{9}$ Studies from South Africa (Salooje Y. Council Against Smoking, South Africa, personal communication, 7 May 1998), Canada, ${ }^{10}{ }^{11}$ and Europe ${ }^{12}$ have also demonstrated the potential role of labels in individuals' decisions to quit smoking. As with other harmful products, providing warning labels is a minimum condition for creating informed consent by consumers.

Although the ability of tobacco warning labels to reduce the enormous harm inflicted by the international epidemic of tobaccoinduced disease is limited, the need for appropriate warning labels is especially great in the developing world. The lack of other information on the adverse health effects of tobacco available in these countries creates a greater need for informative labels displayed in a clear and concise format and in an appropriate language. Warning labels in developing countries may therefore have a larger impact on tobacco consumption than similar information in a developed country, as the South African experience suggests. In developing countries, particularly, requiring warning labels can be an important first step in having governments acknowledge the dangers of tobacco, potentially locking them in for further action. On moral grounds alone, there is no justification for providing one group of consumers with one set of scientific information, while denying similar information on the same product to others, based solely on their country of residence.

Few studies of tobacco warning legislation worldwide have been conducted in this decade. A 1993 report concluded that, of the 77 countries requiring warnings in 1991, 44 did no more than state that smoking may be dangerous to your health. ${ }^{13}$ Recently, the European Union (EU) commissioned a study to determine which countries were in compliance with the 1992 EU directive on tobacco labelling. Although most countries were in compliance, many companies undermined the laws by perhaps intentionally poor colour choice and package design. ${ }^{12}$ Our report is the only recent systematic survey of international cigarette labelling.

\section{Methods}

We conducted a cross-sectional study of international cigarette labelling laws. Data collection was conducted through the internet. We joined GLOBALink (www.globalink.org), a listserve for approximately 700 anti-tobacco activists in 56 countries managed by the International Union Against Cancer. Applicants are screened to exclude pro-industry persons. GLOBALink members include nongovernmental organisations, academics, educators, and legislative staff.

In October 1997, we posted an initial brief letter on GLOBALink requesting that recipients mail, email, or fax us specific information (see below) on cigarette labels in their country and actual Marlboro and Camel cigarette packs. The initial posting yielded responses from nine countries. If a response left some questions unanswered or required clarification, we initiated an email correspondence with the respondent. We posted the letter again three weeks later and received six more responses. We then wrote personalised letters to selected GLOBALink members from countries that had not yet responded requesting the same information, resulting in 14 additional responses. In February 1998, we sent letters to all GLOBALink representatives of countries from which we had received no response; this yielded another 16 responses, for a total of 45 .

With the exceptions of China, Indonesia, and Singapore, all information was gathered directly from GLOBALink members. A GLOBALink member in an American congressman's office provided us with existing legislation from the Library of Congress for those three countries.

Most respondents provided English translations of the laws. A published article was used for the translation of the Japanese label. ${ }^{14}$ Fluent speakers of foreign languages at the University of Michigan were contacted to translate the remaining warnings.

We developed a health warning content score based on warnings that either occur in the present American labels or in the EU directive. The presence (assigned a point) or absence (no points) of the following 10 concepts in the warning law produced a 10-point content scale: addiction, lung cancer, benefits of quitting, other warnings, cancer, pregnancy, emphysema, secondhand (environmental) tobacco smoke, heart disease, and "smoking kills". If a country mentioned "lung cancer" only, it did not receive another point for "cancer". Each country could receive no more than one point for the "other warnings" category. A point was assigned even if the wording on a label did not match our wording exactly - for example, "lung disease" instead of "emphysema". No distinction was made between warnings that said, for example, "Cigarettes cause cancer" and "Cigarettes may cause cancer," because this would be difficult to quantify. The content score assigned to each country was reached by consensus of the three researchers.

Other elements of health warnings are also critical in assessing overall warning quality, but did not lend themselves to being combined with the content score into a single quality score. The following criteria were also evaluated, either by inspection of the pack or from descriptions of the law provided by the respondents: voluntary or required by law, language of warning label, rotating system of warning labels, size of warning label, location of warning label, and requirement to list tar or nicotine levels.

The EU directive requires a constant front label stating "Tobacco seriously damages health." Participating countries can then choose from 15 additional warnings to rotate on the back of the pack. The front warning was not included in the count of the number of rotating labels. Although all eight Canadian labels can appear on different packs at any 


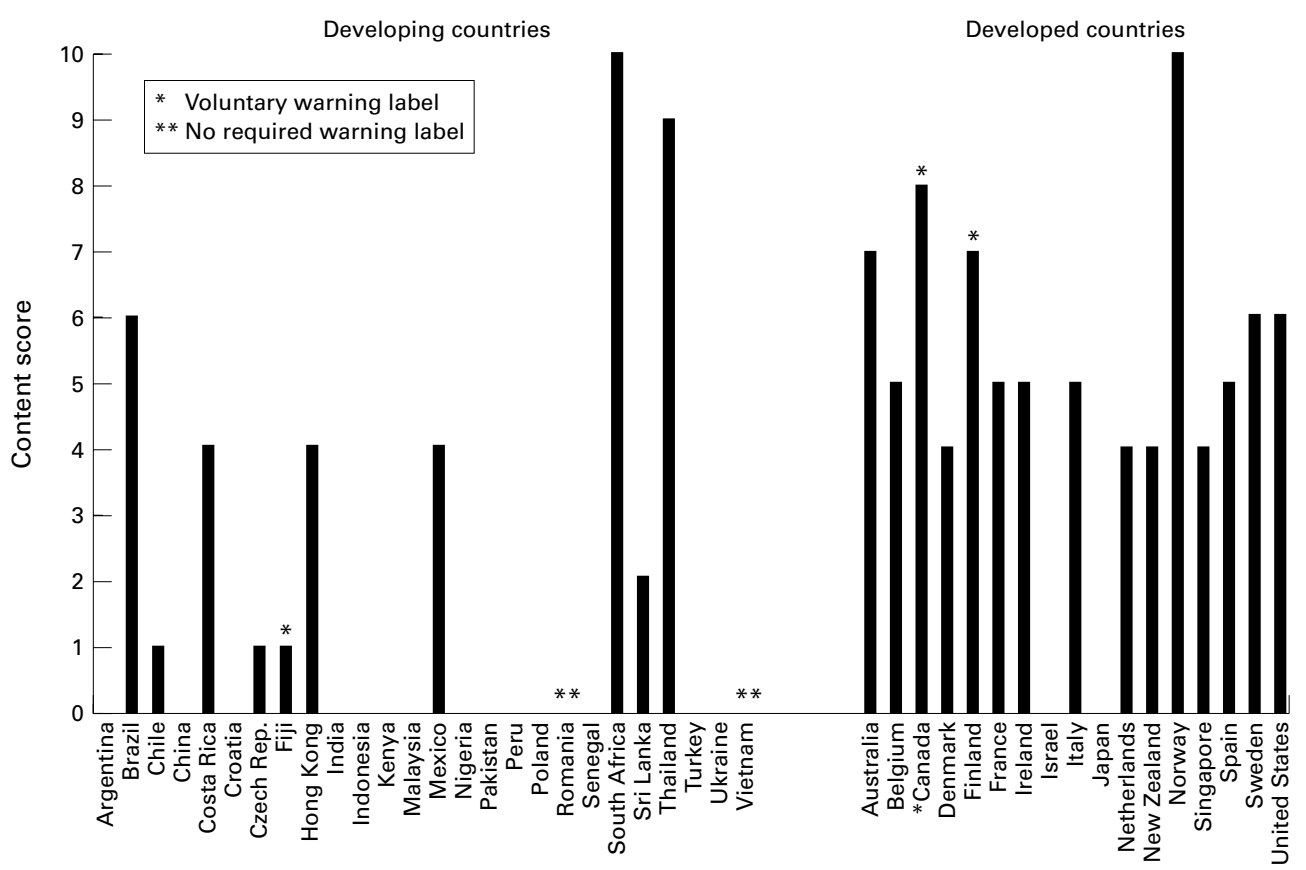

Figure 1 Content of international cigarette warning labels by country.

moment in time (as opposed to appearing sequentially), they were considered to be rotating for the purposes of this study. The size of each warning was measured as a percentage of the surface area of the box, excluding the top and bottom. We included data on size from countries where the respondent provided the size or specified the size required by law. If we received packs, we performed the measurements ourselves. We did not include size data on packs sent to us by fax, owing to the distortion that occurs in the faxing process.

The World Bank lists 133 countries for which adequate economic data are available (there are only limited data available for 76 additional countries), and categorises them as high-income economies or not. ${ }^{15}$ We used these to classify countries as "developed" (27) or "developing" (106). We compared labels from developed and developing countries with the $\chi^{2}$ test for categorical variables and the $t$ test for continuous ones, using the Stata statistical package. ${ }^{16}$ All probability values reported are two-tailed. Our study was limited to cigarettes and excluded information relating to cigars, roll-your-own cigarettes, or chewing tobacco.

\section{Results}

The majority of countries not included in the study, including most of Africa, central Asia, and eastern Europe, were developing countries not represented on GLOBALink. Fifty-six countries were represented on GLOBALink (33 developing and 23 developed), and we received data from $45(80 \%)$ of these countries. The response rate for developing countries represented on GLOBALink was $82 \%$ and for developed countries it was $78 \%$. Twenty-seven of the 45 responding countries $(60 \%)$ were developing nations. Seventeen responding countries $(38 \%)$ were from Europe, 16 (36\%) from Asia, and four each
(9\%) from Africa, South America, and North America.

Forty countries $(89 \%)$ had laws requiring cigarette warning labels. Canada, Fiji, and Finland had voluntary labelling agreements with the industry and Romania and Vietnam had no labelling requirements. American manufacturers always complied with local labelling requirements. In the two countries without labelling requirements, the American packs still provided some health warning. A Marlboro pack obtained from Romania contained an English warning from the United States surgeon general and from Vietnam we received a Marlboro pack with the warning "Smoking is harmful to your health," printed in Vietnamese.

American cigarette packs with the surgeon general's warning printed in English were found in Costa Rica, Mexico, Nigeria, Pakistan, and Romania. Because most of these are non-English speaking countries, these may well have been smuggled packs.

Figure 1 illustrates the overall content scores for the 43 countries for which we obtained detailed labelling information. Sixteen countries, in addition to Romania and Vietnam, scored zero because, although they had a general health warning-for example, "Ministry of Health warning: tobacco is harmful to health" in Kenya-they failed to meet any of our specific content score criteria.

The average content score was 3.0. Generally, warnings in developing countries had weaker content than warnings in developed countries, which were themselves inadequate. The average content score for developing countries was 1.6 , while the average score for developed countries was 5.0 ( $\mathrm{p}=$ 0.0003). However, some developing nations received high scores, while some developed nations fared poorly. Most notable were South 
Africa, which received a score of 10 , and Thailand, with a score of 9. In contrast, Japan scored zero for its only label, "As smoking might injure your health, let's be careful not to smoke too much."14

No specific warning appeared in more than $50 \%$ of countries. Warnings about heart disease appeared most frequently (21 of 43 countries) followed by pregnancy warnings (19 countries). Warnings about addiction were least common (six countries) and lung cancer was only mentioned on 10 countries' packs.

Every warning was more common in developed countries than in developing countries (figure 2). For six of the 10 warnings, statistical significance $(\mathrm{p}<0.05)$ was reached. Heart disease and pregnancy warnings appeared most often in both developing and developed countries. Addiction warnings occurred least often in both developing and developed nations. The smallest relative discrepancies between the frequency of warnings in developing and developed countries were for emphysema and lung cancer, both of which occurred in $19 \%$ of developing countries and $29 \%$ of developed countries $(p=0.440)$. The largest relative discrepancy was for "smoking kills", which occurred four times as often in developed countries $(47 \%)$ as in developing countries $(12 \% ; \mathrm{p}=0.009)$.

Twenty-three of 45 countries (51\%) required a system of rotating warning labels. Twenty-six per cent of developing countries required rotating warnings, compared with $89 \%$ of developed nations $(\mathrm{p}<0.001)$. Among countries with a rotating system, the mean number of rotating labels was 5.9 (5.5 for developing and 6.1 for developed).

The average size of the warnings for the 25 countries for which size data were available, expressed as a percentage of the total pack surface area excluding top and bottom, was $7.5 \%$ (6.1\% for developing countries, $8.5 \%$ for developed countries; $\mathrm{p}=0.325$ ).

For the analysis of the location of the warning label, we excluded the developing countries from which no information on location was received, and the two developing countries which had no legal requirement for location. As table 1 indicates, most labels for developing countries $(73 \%)$ appeared on the side of the pack only, whereas most labels in developed

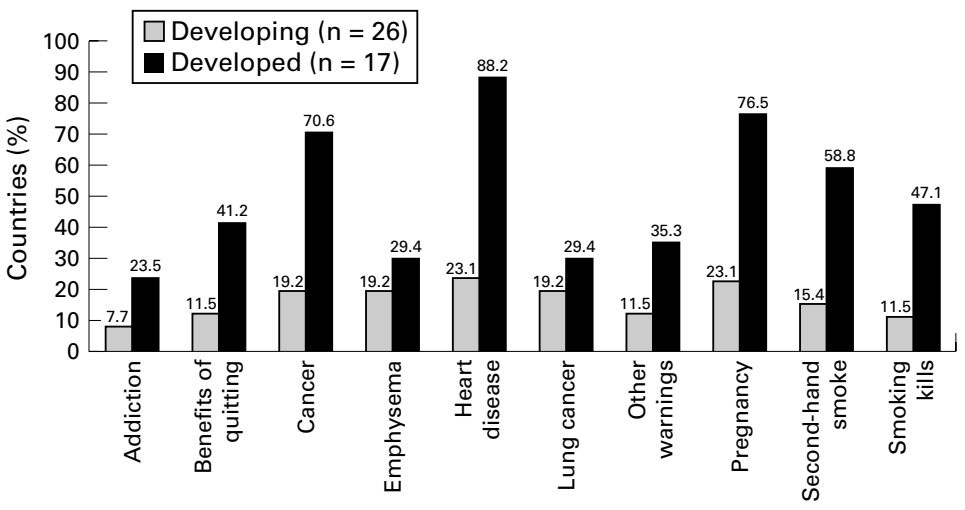

Figure 2 Specific warnings in developing and developed countries.
Table 1 Location of cigarette warning labels

\begin{tabular}{lrlc}
\hline & $\begin{array}{l}\text { Side only } \\
n(\%)\end{array}$ & $\begin{array}{l}\text { Front only } \\
n(\%)\end{array}$ & $\begin{array}{l}\text { Front and back } \\
n(\%)\end{array}$ \\
\hline Developing $(\mathrm{n}=15)$ & $11(73)$ & $1(7)$ & $2(20)$ \\
Developed $(\mathrm{n}=18)$ & $3(17)$ & $1(6)$ & $14(78)$ \\
Total $(\mathrm{n}=33)$ & $14(42)$ & $2(6)$ & $17(52)$ \\
\hline
\end{tabular}

countries $(78 \%)$ appeared on the front and back of the packs $(p=0.003)$. Ten of the 14 countries with front and back warnings were members of the EU.

Sixty-three per cent of the 41 countries providing us with appropriate data had laws requiring tar or nicotine levels to be displayed on the pack. Again, consumers in developing countries received less information: $48 \%$ of developing countries required tar or nicotine levels compared with $83 \%$ of developed countries $(p=0.019)$. Australia and Canada also require carbon monoxide levels to be printed on the pack.

Packs from 24 countries (53\%) were received. In every case, the pack corroborated the information we received by mail, fax, or email from the GLOBALink representative.

\section{Discussion}

The American tobacco industry is supplying residents in developed countries with one set of information while denying residents in developing countries similar information. The American labels had a content score of 6 (itself inadequate) whereas the rest of the world received an average content score of 2.9. Because the American companies generally provide no more information than required by local law, these foreign scores reflect American cigarette labelling abroad.

In almost everything we measured (content score, specific warnings, rotating system of warnings, location, and tar/nicotine levels), labels in the developed world were far superior to those found in developing nations. The average content score for all developed countries was an unacceptable 5.0 and for developing countries was 1.6. Two developing countries (South Africa and Thailand) actually surpassed the American warnings in content. The study was unable to assess such important elements of labels as the size of the border around the warning or the use of contrasting colours. Overall warning label quality is a function of multiple elements, but as there was no clear way to combine them, we do not present a summary quality score.

This study was limited to countries found on GLOBALink, $59 \%$ of which are developing countries. Because developing countries were proportionately underrepresented (by the World Bank definitions used here, $84 \%$ of countries are developing countries) and their average content scores were lower, the actual disparity in the content of warning labels between the developed and developing worlds is probably even greater.

Our data were based on self-reported information from anti-tobacco activists. Whenever possible, we checked respondents' information against actual packs to confirm 
that their reports were accurate. We received packs from $53 \%$ of countries and in every case the information received from the contacts corresponded to the information presented on cigarette packs. In addition, after stratifying by developed $v$ developing country status, there was no difference in the average content score between countries from which we did and did not receive packs (data not shown).

Several countries had innovative labelling systems. South Africa has a system of rotating warning labels that appear in pairs on the front and back of the pack. The front health warning is brief and in a large font, whereas the back warning provides more details on the front warning, as well as a telephone number for those who want information or help quitting. Iceland has a pictogram to accompany each label. ${ }^{13}$ Italy has a warning that informs consumers that "Each year smoking kills more people than car accidents." One Singapore label emphasises in personal terms that "Smoking harms your family." 17 Since the completion of our study, more stringent warning labels have taken effect in Poland.

Foreign governments must not leave the fates of their citizens in the hands of the legislators in the United States or other developed countries. Even if American companies, for example, were to provide foreigners with the same information as they provide American consumers, local or non-American companies could still provide inadequate information. Each country must therefore act now to require its own strong health warning labels. If a given country were to pass legislation requiring warning labels more stringent than those required by the exporting country, the local law should take precedence. Local health officials should determine if their labels are superior to the labels in the exporting country. Local health activists could use the presence of better foreign labels to pressure their governments to raise standards for domestic products.
Although the developed world cannot on its own curb global tobacco consumption, the United States is the world's largest exporter of tobacco and bears a particular responsibility for mitigating the harmful effects of its products. Providing consistent information on the hazards of tobacco to all consumers, regardless of where they live, should be a minimum element of any international tobacco control programme.

The authors wish to express their appreciation to the dozens of GLOBALink members around the world who answered our questions and sent us cigarette packs. We also thank the members of our research-based activism class in the residential college at the University of Michigan for helpful feedback.

1 World Health Organization. World Health Report 1999: Making a difference. Chapter 5: Combatting the tobacco Making a difference. Chapter 5: Combatting the tobacco epidemic. Geneva: WHO, 1999. http://www.who.org/tob/ firms. USA Today 1997 Aug 8.

3 Akhter M. Expanding a deadly export business. Washington Post 1997 Sep 11.

4 Philip Morris Holdings Corporation. 10-K report for the year ending December 31, 1997.

5 Gould S, Miller JY. Tobacco companies look to overseas as Americans snuff out habit. Houston (Texas) Chronicle 1998 Apr 18.

6 World Health Organization. The smoking epidemic-a fire in the global village. Press release, 25 August 1997, www.who.

7 Carlsen W. Tobacco firms find new markets abroad: sales are soaring in poor nations. San Francisco Chronicle 1997 Jun 4.

8 Borland R. Tobacco health warnings and smoking-related cognitions and behaviours. Addiction 1997;92:1427-35.

9 Borland R, Hill D. Initial impact of the new Australian tobacco health warnings on knowledge and beliefs. Tobacco Control 1997;6:317-25.

10 Anon. Cigarette packaging study: the evaluation of new health warning messages. Health Canada, Tandemar Research, 1996

11 Mahood G. Canadian tobacco package warning system. Tobacco Control 1995;4:10-14.

2 Naett C, Howie C. The labeling of tobacco products in the European Union. Brussels: European Bureau for Action on Smoking Prevention, 1995.

13 Roemer R. Legislative action to combat the world tobacco epidemic. Geneva: World Health Organization, 1993.

14 Levin MA. Smoke around the rising sun: an American look at tobacco regulation in Japan. Stanford Law and Policy Review 1997;8:99-123.

15 World Bank. World development report 1977: the state in a changing world. New York: Oxford University Press, 1997.

16 Anon. Stata statistical software, 6.0. College Station, Texas: State Corporation, 1994.

17 Singapore Government Gazette, Subsidiary Legislation Supplement, No.28, No.5226/93. June 4, 1993, p718. 